\title{
Fictionality
}

\section{Cognition and Exceptionality}

Karin Kukkonen (University of Oslo) and Henrik Skov Nielsen (Aarhus University)

Keywords: embodiment, invention, Ian McEwan, Hilary Mantel, Wolfgang Iser

Abstract: Cognitive and unnatural approaches to literature take very different stances on the issue of fictionality. While cognitive approaches consider everyday nonfictional and literary fictional narratives to highlight their similarities, unnatural approaches to narrative stress the exceptionality of the fictional. This article investigates disagreements and potential points of mutual interest in a dialogue between Henrik Skov Nielsen, representing unnatural narratology, and Karin Kukkonen, representing second-generation cognitive narratology. The dialogue develops through close readings of Ian McEwan's On Chesil Beach and Hilary Mantel's Beyond Black. In a first step, Nielsen defines fictionality for unnatural approaches to fiction as “invention.” Kukkonen argues that there are many mental operations that qualify as invented, such as thought experiments and flights of the imagination, but that do not yet amount to fiction. To arrive at a cognitive definition of fictionality, she proposes to revisit Wolfgang Iser's notion of fiction as an "articulated gestalt" in the light of recent embodied and predictive approaches. In a second step, we discuss the so-called exceptionality thesis. The issue at stake here is whether fictional texts are fundamentally dependent on our general cognitive capacities (a position traditionally held by cognitive narratology) or fundamentally depart from everyday modes of thinking. We revisit the debate in light of the unnatural definition of fictionality as invention and the cognitive perspectives gained through embodied and predictive approaches and arrive at the position that the exceptional does not necessarily defy the cognitive.

Cognitive and unnatural narratology have approached issues of fictionality largely independently of each other. For unnatural narratology, represented in this essay by Henrik Skov Nielsen, fictionality has been something of a sine qua non, while for cognitive narratology, represented here by Karin Kukkonen, the main interest lay in cognitive processes considered the same across fictional and everyday narrative. In what follows, a debate unfolds around two questions: (1) the different ways in which unnatural and cognitive narratology define fictionality and delimit its reach and (2) the degree to which the fictional can be regarded as exceptional. The novels Beyond Black (2005) by Hilary Mantel and On Chesil Beach (2008) by Ian McEwan serve as the basis for a discussion from both perspectives. 


\section{What Is Fictionality?}

The fundamental question of the nature of fictionality introduces the different takes on the topic for unnatural and cognitive narratology.

\subsection{Unnatural Narratology on Fictionality}

From the perspective of Nielsen's position within unnatural narratology, the main point about fictional discourse is extremely simple: fictional discourse invents and should not be treated as if it does not. ${ }^{1}$ In the article "Natural Authors, Unnatural Narratives” (2010), Nielsen argues that standard narratological models of the relationship between narrator and author naturalize the understanding of fictional narratives and of fictionality, in the sense that fictional narratives are understood along the lines of everyday reports: a narrator supposedly reports what he or she “knows.” This naturalizing assumption neglects the huge difference between the constraints narratorial agents are under when they are reporting and when they are inventing. From an unnatural perspective, readers can more easily account for the undisguised inventions and transgressions of reportive language that frequently occur throughout literary history by acknowledging this difference. When techniques of fictionality are employed (e.g., zero focalization in the era of the realist novel), these phenomena cannot helpfully be explained by assuming the existence of a narrator distinct from the author. ${ }^{2}$ Instead, they are techniques at the disposal of an inventing author, not of a narrator modeled on everyday noninventive, reporting language. This is an issue that concerns contextual interpretation rather than the ontology of the alleged storyworld. It makes a large difference for interpretation if readers allow themselves to think of a narrative as overtly made up. ${ }^{3}$ Literary theorists should emphasize rather than downplay or obliterate the difference between reading with the assumption that the story is offered as invented (fiction) and reading with the assumption that the story is offered as reported (nonfiction). This understanding then logically leads to a choice between interpretations that is 
quite consequential: if we assume that a story is reported, we will make inferences about the accuracy (or inaccuracy) of the assertions, including assertions about minds, thoughts, events, and characters. By contrast, from an unnatural perspective reading a story as invented means that some questions (about mnemonic overkill, access to knowledge, telepathy, and mind-reading skills) do not and should not surface because they are pertinent only in noninvented contexts, whereas others, such as the design and intention of invention acquire new importance. This becomes quite relevant in the reading and discussion of On Chesil Beach below. This strand of unnatural narratology, which insists on the differential nature of invented narratives, is also quite explicitly and self-avowedly opposed to cognitive approaches' neglect of, and indifference to, what is specifically fictional about literary and fictional narratives—a neglect that seems to a high degree to persist in second-generation approaches.

Kukkonen and Caracciolo outline the distinction between first- and second-generation approaches:

"First-generation" theories in the cognitive sciences conceive of the mind as based on abstract, propositional representations. Like a computer, the first-generation mind would process information as largely independent from specific brains, bodies, and sensory modalities. By contrast, “second-generation” approaches—a term coined by Lakoff and Johnson (Philosophy 77-78)—reject previous models of the mind as unduly limited to information processing, placing mental processes instead on a continuum with bioevolutionary phenomena and cultural practices. We treat "second-generation cognitive science” as interchangeable with another, more technical-sounding label used by cognitive scientists—-that of "e-approaches” to cognition (Menary; Hutto). Here the e's stand for theories bringing to the fore the enactive, embedded, embodied, and extended 
qualities of the mind. To this list we may add "experiential" and "emotional," since this new paradigm gives experience and emotional responses a much more important role in cognition than first-wave, computational cognitivism. (2014: 268)

Second-generation approaches present a fundamentally different model of the mind. Nevertheless, what the two generations' approaches have in common is that they are both above all theories about the mind, and not specifically about texts or art or fiction. The authors go on to say: "The second-generation cognitive sciences have provoked a profound reorientation of thinking about the mind, the body, and their relationship to natural and cultural environments. We believe that they also have the potential to give cognitive literary study a new direction. This collection of essays, then, is intended as a starting point for building a coherent cognitive approach to literature on the basis of the second-generation framework" (ibid.) What has changed is the understanding of mind, not the assumption of a correspondence between real and fictional minds. A new understanding of real minds and real bodies is assumed to have new explanatory power because the fictional minds and bodies are assumed to behave according to our (new) knowledge about real ones. This seems from an unnatural perspective to limit the value of the framework specifically for the study of fiction in two respects. First, the assumption that fictional minds are like real minds and can be understood and analyzed accordingly is at work in both first-generation and second-generation approaches, as is, more generally, the assumptions that fictional characters are like real characters and, more general still, that fiction is like nonfiction. Emily Troscianko’s 2014 article in the special issue of Style on secondgeneration approaches is paradigmatic in this respect. As her title—-First-Person and Second Generation Perspectives on Starvation on Kafka’s ‘Ein Hungerkünstler’”-already indicates, Troscianko is very concerned with half of what Kafka’s own title denotes—starvation—and 
relatively little with the other half: art. A passage like the following is telling: "So, if we ask whether the story can be considered a cognitively realistic evocation of total starvation, what can we conclude? The absence of hunger is now explained, but other absences arise to take its place.” Fiction is measured with reality’s ruler, and it hardly makes any difference to the interpretation that this is not a report about an actual, living, starving person but a piece of fiction. This perspective is certainly not illegitimate, and Troscianko makes valid points about not imposing values such as glory, purity and beauty on starvation, yet the interpretation would arguably be strengthened if the author considered the role and purpose of the invented as a whole rather than being content with examining the degree to which it is "cognitively realistic" (Troscianko 2014: 335).

Second, the conclusions arrived at by means of these protocols for interpretation often seem from an unnatural point of view unsurprising and unspectacular (indeed, bordering on the trivial) because they often run the risk of stating what is immediately clear to any even remotely competent reader. Examples include Kukkonen and Caracciolo’s (2014) statements that bodily signs of fear and disgust point to those feelings in a character in the text, or that we understand emotions because we are familiar with them through vicarious or lived experience. For example, I find it hard to see the added analytical value of a passage like the following:

What happens here can be understood in terms of what Lawrence Barsalou calls "situated conceptualization.” In Barsalou’s second-generation account, concepts work as “instruction manuals”; we grasp their meaning by experiencing them-vicariously—in concrete situations of action and interaction. The notion of "benevolence," for example, can activate experiential traces of someone being benevolent to us, or it can bring forth 
instances of benevolence in cultural memory (e.g., anecdotes of generous rulers), which also unfold through interactions that situate and exemplify the concept. (ibid.: 266)

The passage, in my opinion, comes dangerously close to saying that we understand the concept because we know what it means, which is not yet interpretation.

\subsection{Second-Generation Cognitive Approaches to Fictionality}

Ellen Spolsky claims in Contracts of Fiction (2015: xv) that accounts that deal with the ubiquity and power of fiction are "not in short supply" in cognitive literary study, and she is quite right. However, even though cognitive narratology discusses predominantly fictional texts, the approach usually does not dwell on the specificity of fiction. Alan Palmer in Fictional Minds (2004) and Lisa Zunshine in Why We Read Fiction (2006) offer no explicit theorization about how the fictional quality of the texts they engage with affects cognitive processes differently from nonfictional texts. Monika Fludernik in Toward a "Natural” Narratology (1996: 43) discusses the issue of fictionality in some detail but concludes that "the basic dichotomy for my model is that between the narrative and the non-narrative" rather than between the fictional and the nonfictional. Indeed, "within the frame of 'natural narratology' the term fictional can be dispensed with” (ibid.). For her, fictionality and narrativity amount to the same thing if one does not confine fictionality "to the traditional sense of the non-historical and the a-referential" but rather brings to the fore its fundamentally constructed nature (ibid.: 42). In his introduction to Storytelling and the Sciences of Mind (2013), David Herman insists that readers of literary fiction do not use different sets of cognitive processes and interpretational protocols from those used by participants in conversations or readers of newspapers. All four of these narratologists underline the continuities between everyday, conversational and literary, fictional uses of narrative, as well as the degree to which narrative patterns of mind-reading (in the case of 
Zunshine and Palmer), narrativization (in the case of Fludernik), and canonicity and breach (in the case of Herman) correlate with what we are likely to find in fiction.

This does not mean that cognitive approaches have no handle on the difference between fiction and nonfiction. Often, a distinction is made between "on-line” and "off-line” processing when it comes to the difference between the cognition of factual or fictional texts. Fiction is always processed off-line; that is, it involves everyday cognitive capacities but uses them without any feedback into our everyday cognition. Jean-Marie Schaeffer (2010) speaks of a reader’s involvement with the "brakes" on, drawing on the capacities for simulation that we use to make sense of real situations but without leading us to act on them as if they were real. Zunshine refers to work by Tooby and Cosmides, suggesting that fiction provides a "source tag” for the narratives that we read that prevents us from integrating Little Red Riding Hood into our understanding of the real world (2006: 66). However, it has also been suggested that cognitive processes that work off-line in the context of fiction might have very real effects; for instance, Kidd and Castano, in "Reading Literary Fiction Improves Theory of Mind”\{Au: correct title, per ref list?\} (2013), propose that literary fiction exercises our cognitive capacities. While the question of whether the increased capacities that follow such workouts can be immediately applied in the everyday needs to be approached with care (see Zunshine 2006: 125), textual strategies associated with literary fiction, such as changes in perspective, are related cognitive capacities.

Cognitive literary narratology assumes a fundamental continuity between cognitive processes in everyday contexts and cognitive processes in fictional contexts. As illustrated by the online/offline model, this does not mean that it would have nothing to say about fiction. We can begin to say even more once we relinquish the traditional understanding of cognition as the processing of propositional information. After all, what we imagine, simulate and project already 
feeds into everyday cognition, and different modes of attentive and mind-wandering thought feed into one another in complex ways while reading fiction. Invention as a criterion for fictionality does not begin to cover the complexities revealed once we take these cognitive aspects into account.

Recent research in psychology and the neurosciences places the made-up, the imaginative and the virtual center stage in human cognition. Paul Harris, in The Work of the Imagination (2000), stresses that games and encounters based on mutual pretense are crucial for children’s social, intellectual, and emotional development. The games of make-believe that underlie Kendall Walton's (1990) notion of artistic mimesis and Jean-Marie Schaeffer's (2010) notion of the "fictional competence" of literary readers are by no means tied exclusively to literary narratives but serve vital developmental roles long before children even learn to read. Lionel Naccache,\{Au: correct spelling, per ref list?\} in Le Nouvel Inconscient (2006), proposes that human consciousness is kept coherent through inventiveness that provides ad hoc explanations for our actions. Finally, research on the so-called default mode network suggests that our minds spontaneously wander into projection of the past and imagination of the future when they are not forced to attend to a particular task (see Raichle 2015; Richardson 2011). The human capacity to invent, to imagine, and to project past, present, and future feeds into everyday cognition just as much as into fiction, and they are by themselves not enough to distinguish fictionality.

Invention does not render any of my mental constructions, be they daydreams, imaginations, or thought experiments, fictional. Given the wealth of material on these modes of cognition (which are often tagged fictional, fictive, etc., in the scientific literature itself), some conceptual clarification is called for. Let us go back to a key work by one of the scholars who can be considered a precursor of cognitive literary study: Wolfgang Iser's The Fictive and the 
Imaginary (1993). Instead of the binary opposition between the fictional and the real, Iser proposes the triad of the real (what is given in the world), the imaginary (what we can imagine, virtually, about it), and the fictional (what, both real and imaginary, has been given a particular form in literature). The fictional emerges from what Iser calls "acts of fictionalization" that release the real from its referential constraints and that give coherence to the unformed imaginary. Mantel's novel Beyond Black might serve as an example for such an act of fictionalization. Here historical events like the death of Princess Diana, the domestic dreams of middle-class Britain, and ghostly voices from the beyond merge into the narrative. The novel ends on the words, "This cake we are having: could we have it iced?” (2005: 451). It is not clear at all whether these words are uttered by a figment of the protagonist Alison's imagination, her new-found spirit guide, or an actual elderly lady sitting in her car. Throughout the novel, Mantel suspends readers in her "act of fictionalization” between what corresponds to the real (Alison's childhood as traumatic or her mind as deranged) and what corresponds to the imaginative (Alison as a psychic who truly interacts with the spirit world), so that "this cake we are having: could we have it iced?" turns out to be the perfect expression of the ambiguity that shapes the design of the novel.

With second-generation cognitive approaches, Mantel's merging of the real and the imaginary can be traced from the conceptual to the resonances that underlie her embodied use of language (see Kukkonen and Caracciolo 2014). The boundaries of Alison’s body seem fluid throughout Beyond Black. When her friend Colette shakes out her skirt at the beginning of the novel, "as she turned it the right way out, she felt a tiny stir of disgust, as if flesh might be clinging to the seams” (Mantel 2005: 3). Alison seems to expand into the world with her corpulent self, her smell and the skin-colored "silk" that she has draped around her promotional 
portrait. Her trauma is closely connected to the scars that mark her thighs, and time and again she feels the need to expand bodily in order to "house" the many voices and spirits that haunt her. Colette’s attempt to control her expresses itself most clearly in her putting Alison on a diet. While some of these embodied aspects of the novel are clearly meant to be the case in the fictional world, others are a figment of the characters’ imagination, and yet others hover somewhere in between. Mantel's novel links these different modes of embodiment. The "extra synthetic skin” of Alison's silk scarf (ibid.: 175) on the studio portrait protects her from the penetrating gaze of her patrons just as her skin protects her body, and it envelops Alison's fragile self just as much as the skin on which her brutal upbringing left its mark.

The imaginary and the real are made to bleed into each other in subtle ways in Beyond Black, demonstrating that acts of fictionalization can be easily extended beyond the merging of historical and imagined events and characters. The strange perception that "flesh might be clinging to the seams” of Alison’s clothing may serve as an illustration. "Flesh” with its associations of the sticky, bloody matter of the human body and of the biblical dimension of temptations to be resisted, is what Colette wants to shake off from the clothing that works as a kind of protective gear for Alison. Even though there is no actual flesh involved, this is a matter of embodied cognition. Readers might catch a slight echo of Colette’s "tiny stir of disgust” thought their embodied meaning-making of the text. Tracing these instances across different levels of embodied language, metaphors, and cultural regimes of the body, reveals a complex situated conceptualization.

If Nielsen’s discussion of “situated conceptualization” (see above) had included the complete passage we wrote about how "benevolence" is conceptualized in the passage from Fielding's Tom Jones we discussed, it would have revealed similarly complex layers of 
embodied and cultural inferences and interpretations. Here Henry Fielding integrates, in what would be an "act of fictionalization,” Squire Allworthy's character, his movements through the well-managed estate, the rising sun, and its metaphorical "goodness.” Situated conceptualizations that arise from acts of fictionalization are intricate environments of human thought, not trivialities. The situated conceptualization of Alison's suspension between reaching out into the world and protecting herself from its aggressions extends across different aspects of embodiment in the text. The conceptualization emerges from the embodied textual details that become available through the analysis of the sticky quality of flesh and skin that bleeds, through thematic instances of skin, silk, and scars in Beyond Black, through the invitation to hesitate over whether what is described can be understood as material or delusory, and finally, through the propositional implications of the final sentence of the novel. It would be beside the point here, I argue, to look for the moment when Mantel asks readers to switch between different protocols of interpretation connected to the real or the imaginary. Instead, Mantel transforms elements that correspond to the real world and elements that draw on virtual imaginings, narrative configurations, and other cognitive processes into a piece of fiction that transcends them. Invention is only a very small part of this process.

\section{How Exceptional Is Fiction?}

The point is well taken, from an unnatural perspective, that we should not conflate the imagined and the constructed with the fictional and that we should avoid the tendency to oppose the fictional to the real. Similarly, it seems fruitful to consider the ways in which historical elements such as the death of Princess Diana tie in with depiction of the domestic dreams of middle-class Britain. It is quite true that "it would be beside the point ... to look for the moment at which Mantel asks readers to switch between different protocols of interpretation connected to the real 
or the imaginary.” It would not, however, be beside the point to distinguish between fact and fiction because the novel as a whole is overtly invented. We are inside that recognized invention, and our recognition of that fact shapes and contextualizes our entire experience. So whether or not invention is considered a small or large part of the process, it is its very governing principle. Interpretation based on the assumption of invention does not apply at a specific moment but overall. It is certainly true that readers cannot be content with stopping at declaring that the novel is fictional and invented, but the fact this it is not sufficient to do so should not lead to the conclusion that it is not necessary. It verges on non sequitur to assume that "Mantel does not ask readers to switch between different protocols of interpretation connected to the real or to the imaginary.” True, we don't switch back and forth, from line to line, and from section to section in a futile attempt to distinguish, within the novel, between the real and the imaginary. This, however, does not change the fact—but, rather, is actually contingent upon it - that we read the novel as a whole as globally invented, and that Mantel does ask us to do so. The rhetorical approach to unnatural narratology, which Nielsen generally reflects, assumes that readers and receivers inevitably make assumptions about the invented or noninvented nature of narratives and that authors and senders strongly expect them to. Testimonies are one case in which the absence of any intentional invention is a strong default expectation. Discussions about hoaxes also strongly attest to the fact that we do make such assumptions and feel guided to do so.

A second-generation cognitive approach, which underlies Kukkonen’s argument, would insist that Nielsen jumps too quickly from testimonies and hoaxes to fiction here. From Kukkonen's perspective, the engagement with fiction depends on the particular textual design enabled by acts of fictionalization. Such textual design lends a global coherence to the text, but the account of fiction that emerges from it cannot be satisfyingly defined through "invention" 
and its (posited) interpretive protocols, since these also apply to imaginary activities more generally. Fiction would then be a specific, text-based transformation of the everyday thought processes connected to the real (or noninvented) and the imaginary (or invented). At this point, it might be worth reexamining the suggestion that unnatural narratology considers fictional mind in texts as exceptional and that cognitive narratology considers them as parallel to the everyday (see Herman 2011). After all, invention, as we have seen, is an everyday cognitive process.

\subsection{Unnatural Narratology on the Exceptionality Thesis}

Invention, in the unnatural perspective outlined above, is essential to fiction and to fictional discourse in general. This does not in and of itself make fictional discourse unnatural, of course. Fictional discourse becomes unnatural when it transgresses the limits naturally associated with nonfictional discourse. This transgression does not happen in all fictional discourse, but it is also not limited to overtly antimimetic narratives. In the following we examine the consequences of this in the fairly realist, nonexperimental novel, On Chesil Beach.

In the introduction to his Emergence of Mind (2011), David Herman develops an extensive refutation of what he calls the exceptionality thesis. He directly connects this thesis to the question of unnatural narratology and to theorists like Jan Alber, Maria Mäkelä, Brian Richardson, and Nielsen (ibid.: 11). Herman goes as far as to enroll all the contributors to Emergence of Mind in the quest for similarity between fiction and nonfiction when he states that "the questioning of the Exceptionality Thesis is in a sense the starting point for all the approaches to fictional minds outlined by the chapters in this volume” (ibid.: 18). Herman refers to almost every contributor in the volume as "anti-exceptionalist" (ibid.: 20, 21, 22). What, then, is the exceptionality thesis? 
The exceptionality thesis posits that we approach fiction and nonfiction by means of different protocols for reasoning and with different interpretive strategies and that, for example, “readers’ experiences of fictional minds are different in kind from their experiences of the minds they encounter outside the domain of narrative fiction" (Herman 2011: 8). This is the "thesis against which I think this volume militates,” writes Herman (ibid.: 32). He goes on: “Granted, fictional narratives have the power to stipulate as true reports about characters' mind-contents. But the onus is on Exceptionalists to demonstrate that readers have to use different interpretive protocols to make sense of such stipulated mental states and dispositions, in comparison with the protocols they use for construing actual minds” (ibid.: 33). The rest of this section is about conflicting views on this issue and possible ways to mitigate them. In fact the text Herman himself chooses, Ian McEwan’s On Chesil Beach (2008), seems to Nielsen an excellent illustration of the degree to which it might be profitable to use different interpretive protocols when the mind-content of characters (other than that of a character narrator herself/himself) are rendered. ${ }^{4}$

If parts of unnatural narratology build on an exceptionality thesis, it is equally clear that Herman subscribes to a similarity thesis: "Encounters with fictional minds are mediated by the same heuristics used to interpret everyday minds” (2011: 18). Similarly, along the same lines of imposing naturalization as a necessary human reading strategy, which unnatural narratology questions, Fludernik famously stated in her canonical cognitively oriented text, "When readers read narrative texts, they project real-life parameters into the reading process and, if at all possible, treat the text as a real-life instance of narrating” (2011: 623). From an unnatural point of view, this is not true at all. The main objection is that treating fictional texts as real-life instances of narrating is a choice, not a necessity. Many readers will change interpretational 
strategies when assuming that they are invited to read something as fictionalized. It is an available option to interpret the narrative as inventing in the sense of being unrestricted by referentiality, indexicality, or truth.

McEwan's novel On Chesil Beach is one of three literary examples - the other two are Middlemarch and Tom Jones - quoted and discussed by Herman in order to roughly track some of the developments in the representation of minds over the centuries. Herman himself summarizes his diachronic findings: “To synopsize: passage A [from Tom Jones] reveals considerable variation in the degree to which parts of the narration are grounded in characters' perceptions and evaluations; passage B [from Middlemarch], less variation on this score; and passage C [from On Chesil Beach], even wider variation than A when it comes to shifts in the degree to which reports are tied to characters' standpoints” (Herman 2011: 29). Curiously, there is no explicit, or even implicit, correlation between the use to which these examples are put and the findings and tentative conclusions drawn from them, here at the end of Herman's introduction, and the strong claims about fictional minds made in the course of the introduction's preceding eighteen pages. These claims culminate in Herman's identification of his “larger point": "But my larger point is that what I have termed the Exceptionality Thesis can be questioned from two directions: on the one hand, by arguing that encounters with fictional minds are mediated by the same heuristics used to interpret everyday minds (call this the Mediation argument); on the other hand, by arguing that everyday minds can be experienced in ways that the Cartesian premises of commentators like [Käte] Hamburger and [Dorrit] Cohn disallow (call this the Accessibility argument)" (ibid.: 18). Now, this is spectacularly not true about On Chesil Beach. The novel seems, as a whole, to be one long demonstration (1) that affective and emotional states do not become visible to others, and (2) that encounters with fictional minds are 
not mediated by the same heuristics used to interpret everyday minds. The very book chosen by Herman himself thus seems to confirm Cohn's point in The Distinction of Fiction as discussed by Herman about readers of fiction having access to fictional minds in a way that goes beyond what is possible access to real minds. ${ }^{6}$

Dozens of pages of On Chesil Beach detail the two main characters' thoughts on their wedding night. Edward is brimming with desire and expectations, while Florence dreads the physical intercourse they both imagine will have to take place. The reader gets authoritative access to two separate minds that do not have access to each other, and each of which perpetually grossly misread each other. In the hotel room, about to go to the bed together, Florence is thinking "anything but this” (McEwan 2008: 27) and "there was nothing she could do, beyond fainting” (ibid.). Edward, however, represented here partly in free indirect discourseID\{Au: please spell out.\} is thinking about her "beautiful light brown eyes, bright with undeniable passion, and the faint trembling in her lower lip, which even now she wetted with her tongue” (ibid., emphasis added). The scene goes on, and the irony gradually becomes excruciating, that is, when Florence is on the verge of vomiting: "If she was sick into his mouth, was one wild thought, their marriage would be instantly over” (ibid.: 29). The sound Florence then involuntarily makes is completely misinterpreted by Edward: "When he heard her moan, Edward knew that his happiness was almost complete” (ibid.: 30).

The reader's reading of Edward's mind is very different from Edward's reading of Florence's mind because as readers we are not constrained by the premises that so limit the characters' readings of each other. Edward's thoughts come to us as authoritative and not as something to interpret or to make educated guesses about. We know what he thinks because it is not reported, not expressed in bodily gestures and actions, and not mediated by the heuristics 
used to estimate the feelings and thoughts of real people around us; rather, it is invented. We also know that it is wrong and that the possibility of it being wrong hinges on the fact that Edward (unlike the reader) has to rely on an interpretation of exactly such bodily gestures, which are open to misreading.

The entire book revolves around the theme that the reader knows the affective and emotional states of the characters and knows that they do not become visible to others. We get this right because we read with the premise that the book's characters are fairly realistic and therefore often misinterpret each other because their minds are anything but transparent to other characters and their expressive phenomena anything but unambiguous. On the other hand, the question never arises for readers whether we can know what the characters think about these matters. ${ }^{7}$ We know that Edward thinks that Florence is full of desire, and we know that she is fearful and to some degree repelled by the thought of the physical encounter. The reader uses, and has to use, a completely different heuristics for encountering the characters' minds than for encountering everyday minds. The reader does not arrive at conclusions about Edward's and Florence’s fears and desires by means of interpretation, and certainly not by means of interpreting bodily gestures, because they are directly stated. The characters, conversely, like real people, have to rely on interpretation and expressive phenomena and, in their gross and painful misinterpretations, vividly demonstrate that such phenomena are ambiguous and such interpretations fallible.

The text gives us authoritative access to the thoughts of one character at a time and authoritative access to the fact that this character does not have access to the mind of another character. We get access to a mind that does not have access to another mind. This has everything to do with the question of fictionality. ${ }^{8}$ The understanding that readers can 
unambiguously know what the characters are unable to know about each other and cannot misread how these minds misread each other hinges on a conception of fiction where the minds and their contents are communicated as invented and hence not subject to doubt and interpretation as far as the explicitly communicated parts go. The kind of access to mind we have in the examples cannot be attributed to a fact-reporting narrator or given in expressive phenomena but is intentionally signaled as invented by the author: "The characters in this novel are inventions and bear no resemblance to people living or dead ... I.M.” (169 n.p.). ${ }^{9}$

\subsection{Cognitive Narratology Revisits the "Exceptionality Thesis"}

The understanding of other minds is often taken as the standard by which we understand the fictional text. For example, Gregory Currie writes, "Interpreting a work of fiction is much like interpreting a person” (1990: 100), and Lisa Zunshine applies “source tags” (of different nature) both to levels of interpersonal social complexity and to the distinction of the fictional text (2006: 64ff.; see also Palmer 2004). This is hardly a coincidence. The question of minds and access to minds plays a crucial role in several of the most canonical earlier studies of the distinction between fiction and nonfiction. It figures prominently and explicitly in Cohn’s works Transparent Minds (1978) and The Distinction of Fiction (1999); it is present in the idea of origo in Hamburger (1994), and even to some degree in the concept of reflector figure in Stanzel (1985). It is remarkably decisive, albeit not at all immediately apparent, in Genette’s hugely influential concept of focalization and the distinction between the questions, who sees? and who speaks?, where "the different ways in which narratives can give us access to minds are the very means by which narratives are typologized” (Nielsen 2013: 75). It is not hard to understand, therefore, why David Herman is especially interested not only in dealing with the question of mind (as cognitive narratology always is) but also in addressing that question simultaneously 
with the question about the distinction of fiction. ${ }^{10}$ Minds, thus, are not only at the very center of cognitive approaches but also at the center of debates about the potential exceptionality or distinction of fiction.

The conceptualization of the mind, however, is continually under development in cognitive psychology and philosophy of mind, enabling cognitive narratology to refine its models. Second-generation cognitive approaches, as pursued by Kukkonen, have recently begun to integrate the predictive probabilistic dimensions of thoughts into accounts of embodiment. In the scientific literature, it has been proposed that the minds of others emerge as graspable through synchronized predictions (Friston and Frith 2015). These synchronized predictions derive from the gestures, movements, and utterances of others, as well as narratives of the self that establish predictive structures. Enactive takes on cognition (which traditionally assume a direct access to other minds) have incorporated the predictive dimension (see Hutto 2017; Gallagher and Allan 2016). The predictive, embodied mind constantly assesses probable scenarios and revises them in light of prediction errors. When readers encounter fictional minds in texts, these emerge from what Kukkonen (2016) calls a “designed sensory flow” of prediction errors, which can render fictional minds transparent or opaque to readers' predictive inferences. The predictive dimension of everyday interaction allows for (usually) fluid coordination in the flow of experience. In the designed sensory flow of the fictional text, however, such coordination can be delayed, revisited, and investigated to a degree well beyond the reach of everyday cognition. Such a perspective allows second-generation cognitive approaches to conceptualize the (potentially) exceptional cognitive work that fictional texts allow the human mind to perform.

Herman constructs the exceptionality thesis as the mark of distinction between cognitive approaches to narrative fiction, which would reject any exceptionality, and unnatural approaches 
to narrative fiction, which would insist on exceptionality and reject any notion that readers supply their real-world cognitive processes when making sense of fictional minds. Herman writes, "What I am disputing . . . is the further inference, based on this initial claim on fictionspecific techniques, that only fictional narratives can give us direct 'inside’ view of characters' minds, and that fictional minds are therefore sui generis, or different in kind from everyday minds” (2011: 8). Several claims are collapsed here. First, the claim that only fictional narratives can give us direct access to other minds is refuted by Herman on the basis of general human cognitive capacities to simulate another's thoughts and emotional states in order to make sense of these states ourselves. I would agree with Herman that such a general human cognitive capacity exists and that we use what we could roughly call imitation to make sense of another's behavior through our own embodied experience. Such processes also contribute to our understanding of the represented thought processes of fictional characters. A second-generation cognitive approach would highlight in particular evidence of how readers supply their own embodied resonances of movements, bodily states, and directions to make sense of written language (see Bergen 2012) and how readers place their body at the disposal of the text, leading to immersive experiences (see Caracciolo 2011).

This does not mean, however, that these cognitive, embodied capacities give us an accurate "inside" view of another mind, as we have in fictional narrative. In other words, Herman's second claim, that fictional minds are not fundamentally different from everyday minds, does not follow from the first. According to the second-generation account that merges embodied cognition and predictive processing, the act of fictionalization leads to a designed sensory flow that for example shifts between first and third-person stances embodied in language within the everyday process of predictions. 
Nielsen observes in his discussion of On Chesil Beach above, "The reader gets authoritative access to two separate minds [in On Chesil Beach] that do not have access to each other, and each of which perpetually grossly misreads the other." The "faint trembling of [Florence's] lower lip" is perceived by Edward as a sign of her desire, and I would argue that not only the character but also readers pick up an embodied echo of the trembling, which helps them make sense of this perception. Yet this by no means implies that Edward is correct about Florence's thoughts, and readers are well aware from other parts of the narrative, where they do get access to her thoughts, that the trembling is a physical sign of her fear of him. The power of this passage lies, I would argue, exactly in the clash between Edward's perception and what readers know. The embodied resonance of the trembling makes this clash more poignant, because readers can share Edward's perception while knowing that he is tragically mistaken. Also the multiple levels of Alison's “flesh” across the physical and the metaphorical enhance each other. Such a duplicity of comprehension, I would argue, is an essential component of fiction and difficult to achieve in a real-world linguistic context (see Kukkonen 2016). It is, in other words, dependent on the articulated gestalt of the fictional that combines and configures language into something different from its everyday, nonfictional guise. The text, however, does not require readers to use "a completely different heuristics" from their everyday cognition, as Nielsen has concluded in the case of On Chesil Beach. Rather, we have a process that transforms and escalates everyday cognition in exceptional ways, while at the same time depending on it for the key realization of misreading. The act of fictionalization, and the attendant articulated gestalt of the text, is not question of piggybacking on ordinary cognition, as Herman would have it, but rather a phenomenon facilitated by the designed sensory flow particular to fictional uses of language. It is exceptional, if you will, but not uncognitive. 


\section{Conclusions and Further Questions}

This dialogue has brought us a long way from our starting point, where fictionality appeared as a field over which unnatural and cognitive narratology were profoundly at odds, to a recognition of points of convergence that could be developed further. We agree that fiction neither reproduces the real nor operates independently from it, but we also draw different conclusions from that fact.

From the point of view of the rhetorical version of fictionality theory presented here, fictionality as a concept is not limited only to fiction but also differs from asserting and reporting language. In this conception fiction is a generic notion encompassing genres such as novels, movies, short stories, and other cultural products that have been conventionalized to such a degree that audiences will recognize typical specimens as belonging to one of these genres. Fictionality, from this perspective, is not a quality of fiction only. Fictionality invites responses to what is given and taken as invented. This rhetorical fictionality theory subscribes broadly to Richard Walsh's framework in The Rhetoric of Fictionality (2007) but aspires to more radically separate the question of fictionality from the question of fiction as a generic notion. Walsh still relies heavily, almost solely, on works paratextually designated as or somehow presented as fiction: "The contextual assumption of fictionality also informs the processing of [the first sentence in The Trial] (because we found the book in the fiction section of the bookshop, or we are reading it for a course on the modern novel, or we have prior general knowledge of Kafka)” (ibid.: 33). Even as Walsh carefully distinguishes fictionality from fiction and aptly suggests that this might contribute to an ongoing paradigm shift, his pragmatic approach means that he is constantly on the verge of collapsing the question of fictionality back into the question of fiction. In the quote above, he comes close to saying that because we know it is fiction, we read it as fiction. 
When fictionality is extricated from fiction in the generic sense, its overwhelming prevalence in numerous areas of society is revealed. From the unnatural perspective, fictionality often has a clear real-world scope. In election campaigns and on home pages it is not infrequently used for outright argumentative purposes. In commercials it is very clear that the fictive (say, singing chocolates) is used to achieve very direct real-world effects (say, consumers buying chocolate they would not otherwise). This does not mean, though, that we can conflate it with, treat it as, or interpret it like noninventive language. If we reflect on the famous narrative turn toward acknowledging storytelling in different disciplines, it is strange to observe that until very recently there has been almost no interest in describing the specific role of invented narratives. Branches of unnatural narratology have pointed to the distinctiveness of some overtly invented narratives and tried to point out that it would be a mistake to treat all narratives according to the same scheme-especially if that scheme itself it based on reportive, conversational, face-to-face storytelling. This makes the question of fictionality one of the core questions in the dialogue between cognitive and unnatural narratology.

From a cognitively informed point of view, processes of imagining and such are ubiquitous in our everyday world, but it would be a mistake to categorize them as the same as fiction and fictionality. Mind wandering, games of make believe, and mere inventions are not formed and structured with the complex layering of meaning that becomes available through fictional text. Acts of fictionalization lead to a clear distinction between fiction and other forms of the imagination. Similarly, from an unnatural point of view it is necessary but not sufficient merely to recognize that fiction is invented. The real task is to examine the consequences and the way such a recognition affects interpretation, as well as the understanding of what fiction does. 
Perhaps the most important question to arise from our dialogue-and the one, possibly, where unnatural narratology and second-generation narratology can mutually benefit the most from each other-is how it is possible that fictional discourse so evidently affects our ideas about what is true and right and real, if the very point of departure is that it is a discourse not limited to describing reality as it is. Unnatural narratology can contribute to emphasizing the latter part of the question; and second-generation narratology, to remembering as well as understanding the former.

We think that fictionality became a shibboleth of the discussion between the approaches because of the different sets of distinctions it brought to the fore and the seemingly obvious conclusion it led us to challenge: the exception is not uncognitive. Overtly fictional narratives are neither unusual nor nonprototypical. Fictionality is just as serious as nonfictionality. Fictionality is not a negation of nonfictionality. Fictional narratives according to unnatural narratology can utilize strategies that stories following the rules of reporting and noninventive language cannot. Acts of fictionalization open new possibilities for texts that nonfictional texts do not have, according to second-generation cognitive narratology. Both perspectives support the view that we should not unwarrantedly assume that the same limits and restrictions apply to all narratives, nor should we think that the fact that the same limits and restrictions may not apply is somehow uncognitive.

Areas of disagreement and debate will undoubtedly remain. From a second-generation perspective, fiction is one of the ways in which cognition extends into the cultural and material environment of the embodied individual and how the latter shapes its social communities. The scope of what we call "fiction” might be different here. While Spolsky includes relics and journalist photography in Contracts of Fiction, as part of a homeostatic system creating 
“communal stability in an ever-changing world” (2015: 8), one could point to the specificity of "literary designer environments," created through the virtual world of text and through the networks of intertextuality in what we more generally call "literature” (see Kukkonen, forthcoming). The imaginary and the constructed are common in the conglomerate of culture and cognition and can be found in relics, political speeches, and TV ads, but their particular overlap and transformation into fiction, we would argue, are a more particular kind of cognitive encounter that warrants further investigation. Here, an alliance between unnatural and cognitive narratology could really come into its own, exploring how exactly the sensory flow of literary, fictional language is designed in innovative, inventive ways and how it enhances embodiedness beyond the parameters of the real and the imaginary.

\section{References}

Alber, Jan. 2014 "Postmodernist Impossibilities, the Creation of New Cognitive Frames, and Attempts at Interpretation,” in Beyond Classical Narration: Transmedial and Unnatural Challenges, edited by Jan Alber and Per Krogh Hansen, 261-280 (Berlin: Walter de Gruyter).

Altes, Liesbeth Korthals. 2014 Ethos and Narrative Interpretation: The Negotiation of Values in Fiction (Lincoln: University of Nebraska Press).

Bergen, Benjamin K. 2012 Louder than Words: The New Science of How the Mind Makes Meaning (New York: Basic Books).

Caracciolo, Marco. 2011 “The Reader’s Virtual Body: Narrative Space and Its Reconstruction,” Storyworlds 3: 117-38. 
Caracciolo, Marco. 2014a "Beyond Other Minds: Fictional Characters, Mental Simulation, and ‘Unnatural’ Experiences,” Journal of Narrative Theory 44, no. 1: 29-53.

Caracciolo, Marco. 2014b The Experientiality of Narrative: An Enactivist Approach (Berlin: De Gruyter).

Caracciolo, Marco, and Karin Kukkonen. 2014 “Cognitive Literary Study: Second Generation Approaches,” Style 48, no. 3: 261-74.

Cohn, Dorrit. 1978 Transparent Minds: Narrative Modes for Presenting Consciousness in Fiction (Princeton: Princeton University Press)

Cohn, Dorrit. 1999 The Distinction of Fiction (Baltimore: Johns Hopkins University Press).

Currie, Gregory. 1990 The Nature of Fiction (Cambridge: Cambridge University Press).

Fludernik, Monika. 1996 Towards a "Natural” Narratology (London: Routledge).

Fludernik, Monika. 2001 “New Wine in Old Bottles? Voice, Focalization, and New Writing,” New Literary History 32, no. 3: 619-38.

Friston, Karl, and Chris Frith. 2015 “A Duet for One,” Consciousness and Cognition 36: 390405.

Gallagher, Shaun, and Micah Allen. 2016 “Active Inference, Enactivism, and the Hermeneutics of Social Cognition,” Synthese doi: https://doi.org/10.1007/s11229-016-12698Hamburger, Käte. 1994 Die Logik der Dichtung 4th edition (Stuttgart, Klett-Cotta).

Harris, Paul. 2000 The Work of the Imagination: Understanding Children's Worlds (Malden, MA: Blackwell). 
Herman, David. 2011 Introduction to Emergence of Mind: Representations of Consciousness in Narrative Discourse in English, edited by David Herman, 1-42. (Lincoln: University of Nebraska Press).

Herman, David. 2013 Storytelling and the Sciences of Mind (Cambridge, MA: MIT Press).

Herman, David. 2013 "Cognitive Narratology (revised version; uploaded 22 September 2013)". the living handbook of narratology, edited by Peter Hühn et al. Hamburg: Hamburg University. URL = http://www.lhn.uni-hamburg.de/article/cognitive-narratology-revisedversion-uploaded-22-september-2013

[view date:19 Apr 2018]

Hutto, Dan. 2017 “Getting into Predictive Processing’s Great Guessing Game: Bootstrap Heaven or Hell?,” Synthese. doi: https://doi.org/10.1007/s11229-017-1385-0

Iser, Wolfgang. 1993 The Fictive and the Imaginary: Charting Literary Anthropology (Baltimore, MD: John Hopkins University Press).

Iversen, Stefan. 2013 “Broken or Unnatural? On the Distinction of Fiction in Non-conventional First Person Narration,” in The Travelling Concepts of Narrative, 141-162. (Amsterdam: Benjamins).

Iversen, Stefan. 2016 “Permanent Defamiliarization as Rhetorical Device; or, How to Let Puppymonkeybaby into Unnatural Narratology,” Style 50, no. 4: 455-62.

Kidd, David Comer, and Emanuele Castano. 2013 “Reading Literary Fiction Improves Theory of Mind,” Science 342, no. 6156: 377-80, doi: 10.1126/science.1239918. 
Kukkonen, Karin. 2016 “Bayesian Bodies: The Predictive Dimension of Embodied Cognition and Culture,” in The Cognitive Humanities, edited by Peter Garrett, 153-67 (London: Palgrave Macmillan).

Kukkonen, Karin. Forthcoming “The Literary Designer Environments of Eighteenth-Century Jesuit Poetics," in The History of Distributed Cognition: Enlightenment and Romanticism, edited by Miranda Anderson, George Rousseau, and Michael Wheeler. Edinburgh: University of Edinburgh Press.

Kukkonen, Karin, and Marco Caracciolo. 2014 “Introduction: What Is the Second Generation?,” Style 47, no. 3: 261-74.

Mantel, Hilary. 2005 Beyond Black (London: Fourth Estate).

McEwan, Ian. 2008 On Chesil Beach (London: Vintage books).

Naccache, Lionel. 2006 Le nouvel inconscient: Freud, Christophe Colomb des neurosciences (Paris: Editions Odile Jacob).

Nielsen, Henrik Skov. 2010 “Natural Authors, Unnatural Narratives,” in Post-classical Narratology: Approaches and Analyses, edited by Monika Fludernik and Jan Alber, 275302 (Columbus: Ohio State University Press).

Nielsen, Henrik Skov. 2013 “Naturalizing and Unnaturalizing Reading Strategies: Focalization Revisited," in A Poetics of Unnatural Narrative, edited by Jan Alber, Henrik Skov Nielsen, and Brian Richardson, 67-93. (Columbus: Ohio State University Press).

Nielsen, Henrik Skov, James Phelan, and Richard Walsh. 2015 “Ten Theses about Fictionality,” Narrative 23, no. 1: 61-73. 
Palmer, Alan. 2004 Fictional Minds: Frontiers of Narrative (Lincoln: University of Nebraska Press).

Raichle, Marcus E. 2015 “The Brain’s Default Mode Network,” Annual Review of Neuroscience 38: 433-47, doi: 10.1146/annurev-neuro-071013-014030.

Richardson, Alan. 2011 “Defaulting to Fiction: Neuroscience Rediscovers the Romantic Imagination,” Poetics Today 32, no. 4: 663-92, doi: 10.1215/03335372-1459845.

Schaeffer, Jean-Marie. 2010 Why Fiction? (Lincoln: University of Nebraska Press).

Spolsky, Ellen. 2015 The Contracts of Fiction: Cognition, Culture, Community (Oxford: Oxford University Press).

Stanzel, Franz. 1985 Theorie des Erzählens (Göttingen: Vandenhoeck and Ruprecht).

Troscianko, Emily. 2014 “First-Person and Second-Generation Perspectives on Starvation in Kafka’s ‘Ein Hungerkünstler,’” Style 48: 331-48.

Walsh, Richard. 2007 The Rhetoric of Fictionality (Columbus: Ohio State University Press).

Walton, Kendall L. 1990 Mimesis as Make-Believe: On the Foundations of the Representational Arts (Cambridge, MA: Harvard University Press).

Zunshine, Lisa. 2006. Why We Read Fiction: Theory of Mind and the Novel (Columbus: Ohio State University Press).

1. There are many different positions among unnatural narratologists with different inclinations and interests. The main positions are represented by Jan Alber, Stefan Iversen, Maria Mäkelä, and Brian Richardson, who have all used unnatural narratology as an umbrella term to cover all sorts of responses to what was perceived as cognitive narratology’s move toward a unified 
theory. A basic assumption of such a united theory would be that all narratives were assumed to be natural narrative and adhere to the rules of face-to-face conversational storytelling. Today the approaches associated with unnatural narratology are scattered across a theoretical spectrum ranging from Richardson, explicitly and emphatically equating the unnatural with the antimimetic ), via Alber’s procognitive stance toward the unnatural (Alber 2014), to Iversen’s (2016) and Nielsen’s (2013) attempt to align (without equating) theories about unnatural narratives and fictionality. This latter approach to unnatural narratives contends that fictionality has to do with invention and therefore does not necessarily result in but does allow for transgression of the limitations of noninventive discourse. In this perspective the naturalizing reading strategy is an active choice and often not a very appropriate one, and not at all a necessary one. Moreover, from the same perspective, Richardson is seen to have inherited an unfortunate dichotomy between (overt) fictionality and realism, when he states that realist works mimic nonfictional discourse.

2. Such signposts are conceived of not as ontological but as culturally and historically variable. Moreover, they do not determine a generic relationship but point to the communicative strategy of invention.

3. See also thesis 7 in Nielsen et al. 2015: 67: “Signaling or assuming a fictive communicative intent entails an attitude toward the communicated information that is different from attitudes toward nonfictive discourse.”

4. See also Caracciolo 2014a; Caracciolo 2014b: sect. 6.4 offers a close reading of the novel.

5. Similarity thesis is courtesy of Stefan Iversen (2013: 145). Compare Liesbeth Korthals Altes’s continuity thesis (2014: 36). 
6. Points 1 and 2 are different claims that do not follow from each other. However, they all follow from the reading of the novel.

7. This does not mean that everything is laid out in the open and that we get the characters' every thought. For example, it is a recurring motif and question in the text whether incest has played a role in Florence’s current dispositions and emotions: "Here came the past anyway, the indistinct past. ... It was late in the evening, and her father was moving about the cramped cabin, undressing, like Edward now. She remembered the rustle of clothes, the clink of a belt unfastened or of keys or loose change. Her only task was to keep her eyes closed and to think of a tune she liked. Or any tune. She remembered the sweet scent of almost rotten food in the closed air of a boat after a rough trip. She was usually sick many times on the crossing, and of no use to her father as a sailor, and that surely was the source of her shame” (McEwan 2008: 99-100). There are so many signs here, but the fact that incest never becomes a manifest truth in the narrative in no way invalidates the point that the reader often gets full, authoritative, indubitable access to Florence's as well as Edward's thoughts. On the contrary, it seems likely that Florence herself does not have a full recollection and that, for her, this part of the past is, exactly, “indistinct."

8. Which is not to say, of course, that all invented stories involve internal or zero focalization; fictional discourse is capable of presenting minds in unnatural ways but is not defined by this property. When we perceive represented minds and thoughts as invented we have the interpretational choice to interpret them as authoritative and unquestionable in a way that would be very strange (and possibly even dangerous) to do with real minds. 
9. I wish to acknowledge my gratitude for Herman’s generosity and untiring willingness to engage in dialogue and exchange. I hope in this and the following section to continue this dialogue and thereby contribute to theory development.

10. See Herman 2013: "Cognitive narratology can be defined as the study of mind-relevant aspects of storytelling practices.” 